\title{
A $p$-FREE $\ell^{p}$-INEQUALITY
}

\section{GRAHAME BENNETT}

Abstract. We show how certain simple $\ell^{p}$-inequalities may be proved by "ignoring the $p$."

Mathematics subject classification (2000): 26D15.

Keywords and phrases: $\ell^{p}$-inequality, majorization, higher order convexity.

\section{REFERENCES}

[1] G. Bennett, Sums of powers and the meaning of $\ell^{p}$, Houston J. Math., 32, 3 (2006), 801-831.

[2] G. Bennetr, An inequality from Moment Theory, Positivity, 11, 2 (2007), 231-238.

[3] G. BennetT, Some forms of Majorization, to appear in Houston J. Math.

[4] G. Bennett, A problem of Knuth, submitted to Amer. Math. Monthly.

[5] P.S. Bullen, A criterion for n-convexity, Pacific J. Math., 36 (1971), 81-98.

[6] G.H. Hardy, J.E. Littlewood and G. Pólya, Inequalities. 2nd edition, Cambridge University Press, Cambridge, 1967. 